\title{
The well-being of children in food-insecure households: results from The Eastern Caribbean Child Vulnerability Study 2005
}

\author{
Elizabeth F Racine ${ }^{1, *}$, Kyle Jemison ${ }^{2}$, Larissa R Huber ${ }^{1}$ and Ahmed A Arif ${ }^{1}$ \\ 'University of North Carolina at Charlotte, Department of Public Health Sciences, 9201 University City Blvd, \\ Charlotte, NC 28223-0001, USA: ' United States Department of Agriculture, Economic Research Service, \\ Washington, DC, USA
}

Submitted 20 September 2007: Accepted 28 October 2008: First published online 23 December 2008

\begin{abstract}
Objective: To examine the relationship between food insecurity and child wellbeing indicators.

Design: Cross-sectional survey conducted in 2344 households with children. The main exposure measure was food insecurity status, which was categorized as food secure or food insecure based on two or more food insecurity questions answered in the affirmative. Multiple logistic regression analysis was used to model the association between food insecurity status and selected child wellbeing indicators.

Setting: Barbados, St. Lucia and St. Vincent and the Grenadines (hereafter St. Vincent), three Eastern Caribbean countries, 2005.

Subjects: A random sample of households with children was identified by the governments of Barbados, St. Lucia and St. Vincent. In-home interviews were conducted by social workers.

Results: One-third (33\%) of households were categorized as food insecure. Foodinsecure households were more likely to include a chronically ill parent $(\mathrm{OR}=$ $2 \cdot 48 ; 95 \%$ CI $1 \cdot 76,3 \cdot 49$ ), a recently divorced parent (OR $=1 \cdot 92 ; 95 \%$ CI $1 \cdot 21$, $3 \cdot 05)$, a child requiring multiple visits to a health-care provider for a disability $(\mathrm{OR}=3 \cdot 98 ; 95 \% \mathrm{CI} 1 \cdot 20,13 \cdot 19)$ or injury $(\mathrm{OR}=1 \cdot 78 ; 95 \% \mathrm{CI} 1 \cdot 12,2 \cdot 83)$, a child with a learning disability $(\mathrm{OR}=2 \cdot 08 ; 95 \% \mathrm{CI} 1 \cdot 16,3 \cdot 74)$ or a child with a physical disability $(\mathrm{OR}=2 \cdot 54 ; 95 \% \mathrm{CI} 1 \cdot 22,5 \cdot 32)$ after adjustment for poverty and other demographic variables.

Conclusions: The results indicate that food-insecure households were more likely to be burdened by child disability (learning and physical), family system disruption (recent divorce and chronic illness) and child health-care needs (for disability and injury) than food-secure households. The implementation of programmes and policies to minimize food insecurity in the Eastern Caribbean may be warranted.
\end{abstract}

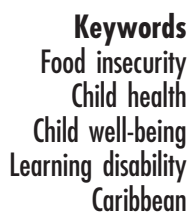

Food insecurity is the limited or uncertain availability of nutritionally adequate and safe foods or limited or uncertain ability to acquire acceptable foods in socially acceptable ways ${ }^{(1)}$. Food insecurity among children can lead to hunger, undernutrition or malnutrition and make children more vulnerable to disease ${ }^{(2,3)}$. Food insecurity has been found to be associated with poverty ${ }^{(4-8)}$, malnutrition and stunted growth $^{(9,10)}$, Fe-deficiency anaemia ${ }^{(11)}$, depression and anxiety ${ }^{(12,13)}$, poor learning among kindergarten and school-aged children ${ }^{(14-16)}$, negative psychosocial outcomes $^{(15)}$, poor social skills among girls ${ }^{(16)}$, poor physical health status ${ }^{(13)}$ and poor emotional well-being ${ }^{(17)}$.

Undernutrition, a measure of energy availability commonly used by the FAO, has been measured to estimate food need in the Eastern Caribbean. The FAO reports that undernutrition affects $2 \cdot 5 \%$ of the population in Barbados, $5 \%$ of the population of St. Lucia, and $10 \%$ of the population of St. Vincent and the Grenadines (hereafter St. Vincent $)^{(18)}$. Studies suggest that children in the Caribbean are more likely than children in developed countries to have stunted growth ${ }^{(19)}$. However, the World Bank classifies Barbados as a high-income country and St. Lucia and St. Vincent as high- to middle-income countries.

Food insecurity in Barbados, St. Lucia and St. Vincent was measured as a component of the Eastern Caribbean Child Vulnerability Study 2005 (ECCVS). The ECCVS measured food security as well as poverty, child health, family structure, education and multiple child well-being indicators among a sample of households with children. The primary objective of the ECCVS was to assess the 
number of children considered 'vulnerable' and to use the results/data to reassess national policies to develop new plans of action for vulnerable children ${ }^{(20)}$.

In the present paper, we hypothesize that food-insufficient households are more likely to report poorer child well-being indicators, specifically in the areas of healthcare utilization, disability, school attendance and family system disruption. Prior studies have not examined the association between food insecurity and the aforementioned child well-being indicators among a large sample of households. This investigation allows for the analysis of a wide variety of child well-being indicators while controlling for potential confounders.

\section{Methods}

\section{Study design and sampling}

The ECCVS was a cross-sectional study conducted by the governments of St. Lucia, St. Vincent and Barbados, with support and technical assistance from $\mathrm{UNICEF}^{(20)}$. The study protocol, methods and questionnaire were reviewed and approved by the National Statistics Offices and Departments of Social Welfare in the three countries, as well as the UNICEF research consulting group responsible for UNICEF research projects and ethics. The analysis was approved by the university institutional review board.

The Central Statistics Office of each country in collaboration UNICEF developed the sampling frame based on population size. As a result, the target number of households per county was 784 in Barbados, 780 in St. Lucia and 780 in St. Vincent (2344 total). From these sampling frames a representative sample of households in all parishes/provinces was selected to represent both urban and rural areas. Within the districts in these parishes/provinces, a sample of households with children under the age of 18 years was selected through the following steps: (i) sampling of wards within these districts; (ii) sampling of towns within each ward; (iii) sampling of enumeration areas (EA) within each town; and (iv) sampling of households in each selected EA. (Wards, towns and EA were selected with probability proportional to size.) For each household, the caregiver provided information on the sociodemographic characteristics (e.g. age, sex, illness status of parents and/or parental survival, orphan status, education, food security status) of all household members.

Social workers visited the selected households and the household was retained in the sample if it contained children. If there were no children in the household the enumerator was instructed to go to the next household (e.g. if there were no children in household 127, then the interviewer went to household 128). Further, moving to the next household did not affect the next household in the enumerator's sequence (e.g. if the sequence was household number 122, 127, 132 and 137, interviewers still visited household 132 even if household 128 was visited in place of 127). If the enumerator encountered a series of households with no children (e.g. a retirement area) they were instructed to knock on every door until finding a household with children and 'catch up' with their enumeration sequence.

Enumerators approached 2436 eligible households for the survey, $100 \%$ included children and $4 \%$ refused to participate resulting in a sample of 2344. Thus, these 2344 households with children were interviewed from May to August 2005 (780 households in St. Lucia, 780 in St. Vincent and 784 in Barbados).

\section{Data collection}

Local social workers were trained to administer in-home surveys. The social workers went door-to-door to introduce and discuss study participation. Potential participants identified as the household caregiver were read an informed consent and explained that participation in the study was fully voluntary. Once consent was given, the social worker began the survey with the caregiver. There were no incentives provided to participants other than the assurance that this information would be used to help in strengthening the countries' ability to identify ways in which the government could improve services to children. Upon completion of the survey, data were entered into a database by a consulting firm hired by the UN.

\section{Instrument}

The Child Vulnerability Survey used in the current study was developed from a questionnaire tool previously used by UNICEF in several developing countries including a Caribbean country, Jamaica. On the basis of this questionnaire, a consultative meeting of representatives from St. Lucia, Barbados and St. Vincent, along with UNICEF representatives and UNICEF consultants, was convened to discuss the questions and ensure that the questions were reflective of local experiences (including food insecurity). The questionnaire was created, tested and used in a cluster survey of seventy households to assess food insecurity and other areas of child vulnerability. Pre-testing took place 4-6 weeks prior to the actual field use of the questionnaire in all three countries. Also, an in-depth qualitative study of household caregivers was conducted using interview guides. Ten households in each country were selected to include food-secure and -insecure households with children. From the qualitative data analysis, the research team identified themes, classified households, created a table of food insecurity cutoff categories, identified questions to add to or delete from the initial questionnaire, and developed and revised answer choices.

The finalized questionnaire used in the ECCVS took 20 min on average to complete and contained seventy items including: who is the caregiver, how many other children are in the home, who else lives in the home, whether the children have their own beds, how many 
pairs of shoes the children have, and whether the home has indoor plumbing. The questionnaire also included items about the health and welfare of the children and the children's parents, whether they lived with their parents, whether someone in the household was employed, whether the children were attending school, and whether any of the children worked outside the home.

\section{Food insecurity variable}

International food security experts suggest that food insecurity instruments measure three domains of food security: anxiety of the availability of food, food quality and food availability (with food availability being the most severe domain $)^{(21,22)}$. In an effort to minimize respondent burden, and because food security was not the focus of the survey, the ECCVS limited the number of food insecurity questions to five questions related exclusively to food availability (Table 1). The questions were derived from the US Department of Agriculture (USDA) eighteen-item US Household Food Security Survey Module ${ }^{(23)}$ and were selected as a result of pre-testing discussed above. Three of the questions selected were very similar to USDA questions ("How often would you say your household has enough food?', 'In the last 30 days did your household ever cut the size of your meals because there was not enough food or money to buy food?', and 'How often have you had to cut the size of your household's meals because there was not enough food or money to buy food?'). The USDA questions regarding skipping meals were modified for the present survey and asked as 'How many meals did your household eat yesterday?' and 'In the last 30 days did your household skip meals because there was not enough food or money to buy food?' In the current analysis, a household was deemed food secure if the caregiver answered zero or one of the food security questions in the affirmative (see Table 1 for cut-off points). Households were categorized as food insecure if the caregiver answered two or more in the affirmative. Similar cut-off points are used in the USDA food security questions ${ }^{(23,24)}$.

\section{Child well-being variables}

In addition to variables measuring food insecurity, eighteen child well-being variables were considered in the following areas: health-care utilization (nine items), school attendance (one item), family system disruption (five items) and child disability (three items). The series of nine health-care utilization questions asked if the child was treated two or more times for a health condition (i.e. flu, diarrhoea, fever, depression or injury). Households were asked whether any children in the households were attending school. We classified a household with one or more school-aged children not attending school based on the whether they attended school and their age: in St. Lucia and St. Vincent, the typical age range of students is $6-15$ years while in Barbados the range is $5-16$ years. The family system disruption variables included a household containing a chronically ill parent (who had been ill for the past 3 months), one or more orphaned children, one or more children who had one deceased parent, children

Table 1 Food security questions asked in the Eastern Caribbean Child Vulnerability Study, 2005 (n 2344)

\begin{tabular}{|c|c|c|c|}
\hline Food insecurity question & Response & $n$ & $\%$ \\
\hline \multirow[t]{5}{*}{ How often would you say your household has enough food? } & Always & 1629 & $69 \cdot 5$ \\
\hline & Sometimes* & 621 & $26 \cdot 5$ \\
\hline & Rarely* & 23 & $1 \cdot 0$ \\
\hline & Never* & 32 & $1 \cdot 4$ \\
\hline & Missing & 39 & $1 \cdot 7$ \\
\hline \multirow[t]{5}{*}{ How many meals did your household eat yesterday? } & None* & 9 & 0.4 \\
\hline & $1^{*}$ & 104 & $4 \cdot 4$ \\
\hline & 2 & 514 & $21 \cdot 9$ \\
\hline & $3+$ & 1685 & 71.9 \\
\hline & Missing & 32 & $1 \cdot 4$ \\
\hline \multirow{4}{*}{$\begin{array}{l}\text { In the last } 30 \mathrm{~d} \text { did your household ever cut the size of your meals because } \\
\text { there was not enough food, or money to buy food? }\end{array}$} & Yes* & 596 & $25 \cdot 4$ \\
\hline & No & 1570 & $67 \cdot 0$ \\
\hline & Don’t know & 21 & 0.9 \\
\hline & Missing & 157 & $6 \cdot 7$ \\
\hline \multirow{6}{*}{$\begin{array}{l}\text { How often have you had to cut the size of your household's meals because } \\
\text { there was not enough food or money to buy food? }\end{array}$} & Always* & 112 & $4 \cdot 8$ \\
\hline & Sometimes* & 673 & $28 \cdot 7$ \\
\hline & Rarely & 202 & $8 \cdot 6$ \\
\hline & Never & 1293 & $55 \cdot 2$ \\
\hline & Don’t know & 27 & $1 \cdot 2$ \\
\hline & Missing & 37 & $1 \cdot \overline{6}$ \\
\hline \multirow{6}{*}{$\begin{array}{l}\text { In the last } 30 \mathrm{~d} \text { did your household skip meals because there was not } \\
\text { enough food or money to buy food? }\end{array}$} & Always & 87 & $3 \cdot 7$ \\
\hline & Sometimes & 471 & $20 \cdot 1$ \\
\hline & Rarely & 120 & $5 \cdot 1$ \\
\hline & Never & 1586 & $67 \cdot 7$ \\
\hline & Don't know & 18 & 0.8 \\
\hline & Missing & 62 & $2 \cdot 7$ \\
\hline
\end{tabular}

${ }^{*}$ Responses considered affirmative. 
living with no family members, and one or more children whose parents divorced within the last year. The child disability questions asked whether any child in the household had a learning, physical or mental disability.

\section{Demographic and poverty variables}

Nineteen demographic and poverty variables were also considered (two demographic items and seventeen poverty items). The demographic variables included country of residency and urban or rural residency. The poverty variables included having three or more household members sleeping per room, whether or not the household had certain possessions (e.g. car) in working order, whether the household had a flush toilet, whether the household had electricity, whether the children had three or more pairs of shoes, whether the children had six or more sets of clothes, whether the children had their own beds, whether the head of household was unemployed (meaning not being employed or being a farmer), and whether the household had piped water.

\section{Statistical analysis}

Cronbach's alpha testing was done to measure the internal reliability of the food security questions. Unadjusted odds ratios and 95\% confidence intervals were calculated to provide a crude association of food insecurity and child well-being, demographic and poverty variables at the household level. To examine the adjusted relationship between poverty and food insecurity, multiple logistic regression was used. In this analysis, food insecurity was the outcome variable with each of the demographic and poverty variables as explanatory variables. Stepwise variable reduction was used to construct the final model between poverty and food insecurity. To examine the relationship between food insecurity and child well-being, child well-being variables related to food insecurity at or below the 0.05 level in bivariate analysis were considered as outcome variables with food insecurity as the exposure variable in multivariate logistic analysis. Demographic and poverty variables that altered the child well-being/food insecurity odds ratio estimates by $10 \%$ or more were included in each of the child well-being logistic regression models ${ }^{(25)}$. All performed tests were two-sided, weighted for country of residence using the PROC SURVEYLOGISTIC command in the SAS statistical software package version 9·1 (SAS Institute Inc., Cary, NC, USA), and results were considered statistically significant at the 0.05 level.

\section{Results}

Of the 2344 households surveyed, 2312 (98.6\%) completed at least one of the food security questions. Cronbach's $\alpha$ was $0 \cdot 81$, indicating good internal reliability among food security questions. Thirty-three per cent of the households were categorized as food insecure. Table 2 presents the unadjusted association between demographic and poverty indicators and food insecurity. Approximately 30\% of the sample acquired their income from sources other than employment and farming. These sources included casual labour, support from family members outside the household and social welfare. Food-insecure households were more common in St. Lucia (43.9\%) and St. Vincent (41.4\%) than Barbados (14.7\%). The majority (66.2\%) of food-insecure households lived in rural areas. Each of the poverty indicators was associated with food insecurity. Of the child well-being indicators, households that had experienced a parental divorce in the previous year $(P=0 \cdot 024)$, a chronically ill parent $(P<0 \cdot 001)$, a school-aged child not attending school $(P<0 \cdot 001)$, a child with a physical disability $(P=0 \cdot 008)$, a child with a mental disability $(P=0 \cdot 007)$, a child with a learning disability $(P=0 \cdot 002)$ and a child treated more than twice for a flu $(P=0 \cdot 016)$, fever $(P=0 \cdot 018)$, disability $(P=0.005)$ or injury $(P<$ $0 \cdot 001$ ) were also associated with food insecurity.

In multivariate analysis, households in St. Lucia $(\mathrm{OR}=2 \cdot 55 ; 95 \% \mathrm{CI} 1 \cdot 89,3 \cdot 42)$ and St. Vincent $(\mathrm{OR}=$ $1.91 ; 95 \%$ CI $1.42,2.56$ ) were at higher risk of food insecurity compared with households in Barbados (Table 3). Among the seventeen poverty indicators, nine were significantly associated with approximately two- to three-fold increased odds of food insecurity after adjustment for other demographic and poverty variables. These were three or more household members sleeping per room, no one in the household with a working car, radio, cable/satellite television or computer, an unemployed head of household, households where children do not have their own bed, households where children have less than three pairs of shoes, and households where children have less than six sets of clothes.

Ten models were constructed between food insecurity and the ten child-well being indicators significantly associated with food insecurity at the 0.05 level in unadjusted analysis (Table 4). Food insecurity was no longer significantly associated with four of the ten child well-being indicators when controlled for demographic and poverty indicators; they were school-aged child not in school, child in the household with a mental disability and child treated more than two times for flu or fever.

Food insecurity was significantly associated with two of the family system disruption indicators of child well-being when controlled for demographic and poverty indicators. Food-insecure households were 1.92 times (95\% CI 1.21, $3.05)$ more likely to have experienced a divorce in the past year and $2 \cdot 48$ times (95\% CI 1.76, 3.49) more likely to have a chronically ill parent (Table 4 ).

Food insecurity was also statistically significantly associated with two of the disability child well-being indicators after adjustment for demographic and poverty indicators. These were presence of a child with a physical disability (OR $=2 \cdot 54 ; 95 \%$ CI $1 \cdot 22,5.32)$ and a child with learning disability $(\mathrm{OR}=2 \cdot 08$; $95 \%$ CI $1 \cdot 16,3 \cdot 74$; Table 4$)$. 
Table 2 Bivariate associations between food insecurity and demographic, poverty and child well-being characteristics among households $(\mathrm{HH})$ with children: Eastern Caribbean Child Vulnerability Study, 2005

\begin{tabular}{|c|c|c|c|c|c|c|c|}
\hline \multirow[b]{3}{*}{ Characteristic } & & & \multicolumn{4}{|c|}{$\mathrm{HH}^{*}$} & \multirow[b]{3}{*}{$P$ valuet } \\
\hline & \multicolumn{2}{|c|}{$\begin{array}{c}\text { All HH } \\
(n 2344)\end{array}$} & \multicolumn{2}{|c|}{$\begin{array}{l}\text { Food secure } \\
\text { (n 1549) }\end{array}$} & \multicolumn{2}{|c|}{$\begin{array}{l}\text { Food insecure } \\
\qquad(n 763)\end{array}$} & \\
\hline & $n$ & $\%$ & $n$ & $\%$ & $n$ & $\%$ & \\
\hline \multicolumn{8}{|l|}{ Demographic and poverty indicators } \\
\hline Barbados & 784 & 33.5 & 662 & $42 \cdot 7$ & 112 & $14 \cdot 7$ & $<0.001$ \\
\hline St. Lucia & 780 & $33 \cdot 3$ & 434 & $28 \cdot 0$ & 335 & $43 \cdot 9$ & $<0.001$ \\
\hline St. Vincent & 780 & $33 \cdot 3$ & 453 & $29 \cdot 2$ & 316 & $41 \cdot 4$ & $<0.001$ \\
\hline Lives in rural area & 1160 & $49 \cdot 5$ & 639 & $41 \cdot 3$ & 505 & $66 \cdot 2$ & $<0.001$ \\
\hline Three or more HH members sleeping per room & 593 & $25 \cdot 3$ & 275 & $17 \cdot 4$ & 318 & $41 \cdot \overline{7}$ & $<0.001$ \\
\hline No one in $\mathrm{HH}$ has a car in working order & 1157 & $66 \cdot 5$ & 885 & $57 \cdot 2$ & 649 & $85 \cdot 3$ & $<0.001$ \\
\hline No one in $\mathrm{HH}$ has a radio in working order & 127 & $5 \cdot 4$ & 36 & $2 \cdot 3$ & 89 & $11 \cdot 7$ & $<0.001$ \\
\hline No one in $\mathrm{HH}$ has a television in working order & 198 & $8 \cdot 5$ & 61 & 3.9 & 136 & $17 \cdot 9$ & $<0.001$ \\
\hline No one in $\mathrm{HH}$ has a cable or satellite television in working order & 1182 & $50 \cdot 5$ & 664 & $42 \cdot 9$ & 500 & $65 \cdot 8$ & $<0.001$ \\
\hline No one in $\mathrm{HH}$ has a telephone in working order & 315 & 13.5 & 119 & $7 \cdot 7$ & 192 & $25 \cdot 2$ & $<0.001$ \\
\hline No one in $\mathrm{HH}$ has a stove in working order & 46 & $2 \cdot 0$ & 9 & 0.6 & 36 & $4 \cdot 7$ & $<0.001$ \\
\hline No one in $\mathrm{HH}$ has a refrigerator in working order & 230 & $9 \cdot 8$ & 73 & $4 \cdot 7$ & 156 & $20 \cdot 5$ & $<0.001$ \\
\hline No one in $\mathrm{HH}$ has a computer in working order & 1606 & $68 \cdot 6$ & 901 & $58 \cdot 2$ & 685 & $90 \cdot 1$ & $<0.001$ \\
\hline No one in $\mathrm{HH}$ has Internet & 1829 & $78 \cdot 5$ & 1088 & $70 \cdot 7$ & 718 & $94 \cdot 6$ & $<0.001$ \\
\hline No electricity in home & 101 & $4 \cdot 3$ & 26 & $1 \cdot 7$ & 75 & $9 \cdot 8$ & $<0.001$ \\
\hline No flush toilet & 710 & $30 \cdot 3$ & 321 & $20 \cdot 7$ & 380 & $49 \cdot 8$ & $<0.001$ \\
\hline Unemployed & 688 & $29 \cdot 4$ & 350 & $22 \cdot 6$ & 327 & $42 \cdot 9$ & $<0.001$ \\
\hline No piped water & 54 & $2 \cdot 3$ & 29 & 1.9 & 25 & $3 \cdot 3$ & 0.036 \\
\hline Children have their own bed & 1048 & $44 \cdot 9$ & 551 & $35 \cdot 7$ & 482 & $63 \cdot 5$ & $<0.001$ \\
\hline Children have less than three pairs of shoes & 309 & $13 \cdot 2$ & 81 & $5 \cdot 2$ & 224 & $29 \cdot 4$ & $<0.001$ \\
\hline Children have less than six sets of clothes & 330 & $14 \cdot 1$ & 120 & $7 \cdot 8$ & 208 & $27 \cdot 3$ & $<0.001$ \\
\hline \multicolumn{8}{|l|}{ Child well-being indicators } \\
\hline Divorce in the last year & 119 & $5 \cdot 1$ & 69 & $4 \cdot 5$ & 50 & $6 \cdot 6$ & 0.024 \\
\hline Any child orphans in $\mathrm{HH}$ & 9 & $0 \cdot 4$ & 6 & 0.4 & 3 & $0 \cdot 4$ & $1 \cdot 0 \S$ \\
\hline Any child in $\mathrm{HH}$ with one deceased parent & 148 & $6 \cdot 3$ & 93 & $6 \cdot 0$ & 54 & $7 \cdot 1$ & $0 \cdot 291$ \\
\hline Chronically ill parent in $\mathrm{HH}$ & 218 & $9 \cdot 3$ & 119 & $7 \cdot 7$ & 95 & $12 \cdot 5$ & $<0.001$ \\
\hline Any child in $\mathrm{HH}$ not a family member & 32 & $1 \cdot 4$ & 24 & $1 \cdot 6$ & 8 & $1 \cdot 1$ & 0.332 \\
\hline Any school-aged children in $\mathrm{HH}$ not enrolled in school & 115 & $4 \cdot 9$ & 57 & $3 \cdot 7$ & 56 & $7 \cdot 3$ & $<0.001$ \\
\hline Any child in $\mathrm{HH}$ with a mental disability & 24 & $1 \cdot 0$ & 10 & 0.6 & 14 & $1 \cdot 8$ & 0.007 \\
\hline Any child in $\mathrm{HH}$ with a physical disability & 38 & $1 \cdot 6$ & 18 & $1 \cdot 2$ & 20 & $2 \cdot 6$ & 0.008 \\
\hline Any child in $\mathrm{HH}$ with a learning disability & 63 & $2 \cdot 7$ & 31 & $2 \cdot 0$ & 32 & $4 \cdot 2$ & 0.002 \\
\hline Any child in $\mathrm{HH}$ treated for fluł & 516 & $22 \cdot 0$ & 321 & $20 \cdot 7$ & 192 & $25 \cdot 2$ & 0.016 \\
\hline Any child in $\mathrm{HH}$ treated for diarrhoea/vomiting & 101 & $4 \cdot 3$ & 62 & $4 \cdot 0$ & 39 & $5 \cdot 1$ & $0 \cdot 220$ \\
\hline Any child in $\mathrm{HH}$ treated for feverł & 180 & $7 \cdot 7$ & 105 & $6 \cdot 8$ & 73 & $9 \cdot 6$ & 0.018 \\
\hline Any child in $\mathrm{HH}$ treated for malnutrition & 5 & $0 \cdot 2$ & 2 & $0 \cdot 1$ & 3 & $0 \cdot 4$ & $0.340 \$$ \\
\hline Any child in $\mathrm{HH}$ treated for depression $\ddagger$ & 15 & $0 \cdot 6$ & 7 & 0.5 & 8 & $1 \cdot 1$ & 0.093 \\
\hline Any child in $\mathrm{HH}$ treated for disability & 15 & $0 \cdot 6$ & 5 & 0.3 & 10 & $1 \cdot 3$ & 0.005 \\
\hline Any child in $\mathrm{HH}$ treated for injury & 102 & $4 \cdot 4$ & 46 & $3 \cdot 0$ & 55 & $7 \cdot 2$ & $<0.001$ \\
\hline Any child in $\mathrm{HH}$ treated for assault & 2 & $0 \cdot 1$ & 1 & $0 \cdot 1$ & 1 & $0 \cdot 1$ & $0.55 \S$ \\
\hline Any child in $\mathrm{HH}$ treated for pregnancy & 3 & $0 \cdot 1$ & 1 & $0 \cdot 1$ & 2 & $0 \cdot 3$ & $0.255 \S$ \\
\hline
\end{tabular}

*These are the 2312 households that answered at least one of the food security questions.

$+x^{2}$ statistic unless otherwise noted.

fIndicates the child treated for the condition two or more times in the past year.

§Fisher's Exact Test.

In addition, food-insecure households were 3.98 times (95\% CI $1 \cdot 20,13 \cdot 19)$ more likely to have a child treated two or more times for a disability in the past year and 1.78 times (95\% CI $1 \cdot 12,2 \cdot 83$ ) more likely to have a child treated two or more times for an injury in the past year (Table 4).

\section{Discussion}

In the present study, one-third of the population was classified as food insecure. However, the burden of food insecurity was found to impact St. Lucia and St. Vincent much more than Barbados. We found that food insecurity negatively impacted child well-being in the areas of family system disruption, disability and health, when adjusted for poverty and demographics. The food insecurity questions had been based on the USDA food security measures and then modified as a result of pretesting. The questions were found to have good internal reliability.

In the area of family system disruption, food insecurity was associated with the presence of a chronically ill parent and a parental divorce in the past year. The authors are unaware of previous research examining the relationship between food insecurity and chronic illnesses of a parent or divorce. However, compromised 
Table 3 Multivariate associations* between demographic and poverty indicators and food insecurity status among households $(\mathrm{HH})$ with children: Eastern Caribbean Child Vulnerability Study, 2005

\begin{tabular}{lrr}
\hline & & $\begin{array}{c}\text { Food insecuret } \\
(n \text { 763) }\end{array}$ \\
\cline { 2 - 3 } Characteristic & OR & $95 \% \mathrm{Cl}$ \\
\hline Barbados & $1 \cdot 00$ & Referent \\
St. Lucia & $2 \cdot 55$ & $1 \cdot 89,3 \cdot 42$ \\
St. Vincent & $1 \cdot 91$ & $1 \cdot 42,2 \cdot 56$ \\
Three or more HH members sleeping per room & $1 \cdot 64$ & $1 \cdot 27,2 \cdot 10$ \\
No one in HH has a car in working order & $1 \cdot 59$ & $1 \cdot 21,2 \cdot 09$ \\
No one in HH has a radio in working order & 1.98 & $1 \cdot 26,3 \cdot 11$ \\
No one in HH has a cable or satellite television in working order & $1 \cdot 69$ & $1 \cdot 33,2 \cdot 15$ \\
No one in HH has a computer in working order & $2 \cdot 39$ & $1 \cdot 74,3 \cdot 26$ \\
Unemployed & $1 \cdot 38$ & $1 \cdot 10,1 \cdot 74$ \\
HH where children do not have their own bed & $1 \cdot 41$ & $1 \cdot 11,1 \cdot 80$ \\
HH where children have less than three pairs of shoes & $3 \cdot 29$ & $2 \cdot 35,4 \cdot 60$ \\
HH where children have less than six sets of clothes & $2 \cdot 54$ & $1 \cdot 89,3 \cdot 41$ \\
\hline
\end{tabular}

*Multiple logistic model includes food insecurity as dependent variable controlled for the demographic and poverty indicators listed above as well as urban $v$. rural residence, piped water in the home, no flush toilet, refrigerator in the home, stove in the home, television in the home, telephone in the home, electricity in the home and Internet in the home.

tOdds of food insecure $v$. food secure; food insecure represents $\mathrm{HH}$ that answered in the affirmative to two or more food insecurity questions.

Table 4 Multivariate associations between food insecurity status and child well-being among households $(\mathrm{HH})$ with children: Eastern Caribbean Child Vulnerability Study, 2005

\begin{tabular}{|c|c|c|}
\hline \multirow[b]{2}{*}{ Child well-being outcome* } & \multicolumn{2}{|c|}{$\begin{array}{l}\text { Food insecuret } \\
\qquad(n 763)\end{array}$} \\
\hline & OR & $95 \% \mathrm{Cl}$ \\
\hline Divorce in the last year $\neq$ & 1.92 & $1 \cdot 21,3.05$ \\
\hline Chronically ill parent in the households & $2 \cdot 48$ & $1.76,3.49$ \\
\hline Any school-aged children in $\mathrm{HH}$ not enrolled in schoolll & 1.05 & $0 \cdot 65,1 \cdot 71$ \\
\hline Any child in $\mathrm{HH}$ with a mental disability & $1 \cdot 83$ & $0 \cdot 66,5 \cdot 07$ \\
\hline Any child in $\mathrm{HH}$ with a physical disability** & $2 \cdot 54$ & $1 \cdot 22,5 \cdot 32$ \\
\hline Any child in $\mathrm{HH}$ a learning disabilityt† & $2 \cdot 08$ & $1 \cdot 16,3 \cdot 74$ \\
\hline Any child in $\mathrm{HH}$ treated for fluł‡, $\S \S$ & $1 \cdot 15$ & $0.92,1.44$ \\
\hline Any child in $\mathrm{HH}$ treated for fever $\neq \pm, \S \S$ & $1 \cdot 27$ & $0.90,1 \cdot 80$ \\
\hline Any child in $\mathrm{HH}$ treated for disabilitył‡,IIII & $3 \cdot 98$ & $1 \cdot 20,13 \cdot 19$ \\
\hline Any child in $\mathrm{HH}$ treated for injurył‡, & $1 \cdot 78$ & $1 \cdot 12,2 \cdot 83$ \\
\hline
\end{tabular}

${ }^{*}$ Those child well-being indicators significantly related to food insecurity in bivariate analysis are adjusted here for poverty variables. tOdds of food insecure $v$. food secure; food insecure represents $\mathrm{HH}$ that answered in the affirmative to two or more food insecurity questions.

$\ddagger$ Adjusted for children with their own bed, no one in $\mathrm{HH}$ has with a television in working order, no flush toilet, country of residence. $\S$ Adjusted for urban $v$. rural residence and country of residence.

IIAdjusted for urban $v$. rural residence, no flush toilet, no one in $\mathrm{HH}$ has a telephone, television, stove, refrigerator and computer in working order, no one in $\mathrm{HH}$ has Internet, children with their own bed, children with less than three pairs of shoes, children with less than six sets of clothes, three or more $\mathrm{HH}$ members sleeping per room.

- Adjusted for no one in $\mathrm{HH}$ has a refrigerator and computer in working order, no one in $\mathrm{HH}$ has Internet, children with their own bed, children with less than three pairs of shoes, children with less than six sets of clothes, three or more HH members sleeping per room, country of residence, unemployment, no flush toilet, and urban $v$. rural residence.

${ }^{*}$ Adjusted for children with their own bed, children with less than six sets of clothes, three or more HH members sleeping per room, no one in $\mathrm{HH}$ has a car in working order, no flush toilet.

t+Adjusted for no one in HH has a car, television and computer in working order, no one in HH has Internet, children with less than six sets of clothes, three or more $\mathrm{HH}$ members sleeping per room.

\#Indicates the child treated for the condition two or more times in the past year.

$\S \S$ Adjusted for country of residence.

IIIIAdjusted for country of residence, three or more household members sleeping per room, no flush toilet, urban $v$. rural residence, no one in $\mathrm{HH}$ has a computer, cable/satellite television and telephone in working order, no one in $\mathrm{HH}$ has Internet.

- Adjusted for country of residence, no flush toilet, urban $v$. rural residence, children with their own bed, no one in household has a radio, television, refrigerator and computer in working order, no one in $\mathrm{HH}$ has Internet and no electricity in home.

nutrition has been repeatedly found to lead to poorer health outcomes ${ }^{(26-30)}$. Food insecurity may lead to poor health of a household member; poor health may inhibit the ability to work, reducing resources available to purchase food for the home. Food insecurity may cause stress that leads to an increased risk of divorce.
In the area of disability, food insecurity was associated with the presence of a child with a learning or physical disability. Previous research in the USA reported an association between food insecurity and learning disorders among migrant and seasonal workers living close to the US-Mexican border ${ }^{(5)}$. Also, previous research has found 
that learning is compromised among food-insecure children as compared with food-secure children ${ }^{(14-16)}$. To our knowledge, the relationship between physical disability and food insecurity has not been previously studied. However, a relationship between physical limitations and food insecurity has been found by Guillford et $a l^{(31)}$ in Trinidad and Tobago. Chronic food insecurity, particularly severe undernutrition, may lead to physical injury and disability. On the other hand, a physically disabled child in the home may require an adult to leave the workforce to care for the child, which would decrease the financial resources available to purchase food.

The present analysis found that children in food-insecure households are more likely to seek multiple visits to a health-care provider for injury and disability. This result supports the reports of physical disability discussed above. Further research is warranted to better understand this relationship.

The series of questions regarding health-care visits may underestimate the number of ill children. Households, particularly those impoverished, may not utilize healthcare services. A focus group conducted as part of the ECCVS found that many families do not fully utilize public health-care programmes ${ }^{(20)}$. Unadjusted results indicated that food insecurity may also be related to flu and fever.

A strength of the present study is that it sampled a large number of representative households ( $n$ 2344) in Barbados, St. Lucia and St. Vincent. Another strength is the high response rate among households with children. Additionally, the survey captured a wide variety of poverty indicators and child well-being indicators, some of which have not been examined in the past, i.e. health-care use, school attendance, learning disability, recent divorce and chronic illness of the parent. Finally, this is a population that has not been well studied. Regions with limited food production, such as the Eastern Caribbean, face additional challenges due to their lack of available land for farming.

The present study has several limitations. First, the food security questions were limited to food availability questions and did not capture information related to food quality or anxiety over the availability of food. Also, the food security questions asked in the analysis did not cover some of the more severe questions about experiences with hunger or weight loss asked in the USDA questionnaire. Therefore we were unable to measure the degree of food insecurity experienced in this population. Second, the temporal relationship between food insecurity and exploratory variables is unclear since the present study was cross-sectional. For instance, food insecurity may increase the risk of divorce or divorce may lead to food insecurity, if the household resources change as a result of the divorce. Third, all responses were selfreported. This may have led to some misclassification; for instance, when asked 'If any of the children in your household have a disability, please tell me what kind of disability?' parents' responses may or may not have been based on the diagnosis being made by a physician.

The results of the study indicate that child well-being is compromised among food-insecure households, in the areas of family system disruption, health-care utilization and disability. At a minimum this means that these households are likely experiencing temporary bouts of hunger and possibly chronic hunger. The degree of food insecurity was not collected in the study. Therefore we cannot estimate acute or chronic hunger. This information may prove useful for programme and policy planning in an effort to address the need for increased food production, nutrition education and supplemental food programmes for families at risk for food insecurity.

\section{Conclusion}

In 2005, one-third of the households with children in Barbados, St. Lucia and St. Vincent and the Grenadines were food insecure to some degree. Local nutritionists and public health educators can work with policy makers to address the issue of food availability within these countries. Families could be screened with a validated food insecurity survey, possibly the Household Food Security Scale ${ }^{(6)}$, in an effort to identify children at higher risk of poor health and education outcomes.

An objective of the present study was to assess the relationship between food security and child well-being. Four areas of child well-being were studied: health-care utilization, disability, school attendance and family system disruption. In a global sense, the results identify some areas for further research. Specifically, future studies should further investigate the relationship between food insecurity and the development of learning and physical disabilities and injuries. Analysis of the relationship between food insecurity and multiple visits for specific health conditions was limited in the current analysis due to the small number of responses by condition. Also, further examination of the impact of parental chronic illness and divorce in a food-insecure family on child well-being may be warranted.

\section{Acknowledgements}

There are no conflicts of interest to report. The results reported herein represent a secondary analysis of The Eastern Caribbean Child Vulnerability Study (ECCVS), which was funded by UNICEF in conjunction with the Governments of Barbados, St. Lucia and St. Vincent. E.F.R. originated the idea for the study, conducted the analyses and led the writing. K.J. served as technical consultant of the ECCVS for UNICEF and then worked with the US Department of Agriculture (USDA), Economic Research Service (ERS) at the time of the secondary analysis and writing of the manuscript. The views expressed in this 
article are those of the author and not necessarily those of the ERS or USDA. He wrote the majority of the methods section and reviewed manuscript drafts. L.R.H. provided methodological guidance and reviewed manuscript drafts. A.A.A. provided statistical guidance and reviewed the manuscript draft. We are grateful for the assistance and support of the UNICEF Office for Barbados and the Eastern Caribbean, particularly Heather Stewart and consultant project coordinator Mark Loudon, as well as all the residents of Barbados, St. Lucia and St. Vincent who participated in the study. We thank Dr Sharon Portwood and anonymous reviewers for their thoughtful comments and Dr Jacek Dmochowski for his statistical guidance.

\section{References}

1. Struble MB \& Aomari LL (2003) Position of the American Dietetic Association: addressing world hunger, malnutrition, and food insecurity. J Am Diet Assoc 103, 1046-1057.

2. Anon. (1990) Core indicators of nutritional state for difficult to sample populations. J Nutr 120, Suppl. 11, 1559-1600.

3. Holben DH (2006) Position of the American Dietetic Association: food insecurity and hunger in the United States. J Am Diet Assoc 106, 446-458.

4. Rose D \& Charlton KE (2002) Quantitative indicators from a food expenditure survey can be used to target the food insecure in South Africa. J Nutr 132, 3235-3242.

5. Weigel MM, Armijos RX, Hall YP, Ramirez Y \& Orozco R (2007) The household food insecurity and health outcomes of US-Mexico border migrant and seasonal farmworkers. J Immigr Minor Health 9, 157-169.

6. Gulliford MC, Nunes C \& Rocke B (2006) The 18 Household Food Security Survey items provide valid food security classifications for adults and children in the Caribbean. BMC Public Health 6, 26.

7. Oldewage-Theron WH, Dicks EG \& Napier CE (2006) Poverty, household food insecurity and nutrition: coping strategies in an informal settlement in the Vaal Triangle, South Africa. Public Health 120, 795-804.

8. Rukuni M (2002) Africa: addressing growing threats to food security. J Nutr 132, 3443S-3448S.

9. Baig-Ansari N, Rahbar MH, Bhutta ZA \& Badruddin SH (2006) Child's gender and household food insecurity are associated with stunting among young Pakistani children residing in urban squatter settlements. Food Nutr Bull 27, 114-127.

10. Renzaho AM (2006) Food insecurity, malnutrition and mortality in Maewo and Ambae Islands, Vanuatu. Public Health Nutr 9, 798-807.

11. Skalicky A, Meyers AF, Adams WG, Yang Z, Cook JT \& Frank DA (2006) Child food insecurity and iron deficiency anemia in low-income infants and toddlers in the United States. Matern Child Health J 10, 177-185.

12. Whitaker RC, Phillips SM \& Orzol SM (2006) Food insecurity and the risks of depression and anxiety in mothers and behavior problems in their preschool-aged children. Pediatrics 118, e859-e868.

13. Bronte-Tinkew J, Zaslow M, Capps R, Horowitz A \& McNamara M (2007) Food insecurity works through depression, parenting, and infant feeding to influence overweight and health in toddlers. J Nutr 137, 2160-2165.

14. Winicki J \& Jemison K (2003) Food security and hunger in the kindergarten classroom: its effect on learning and growth. Contemp Econ Policy 21, 145-157.

15. Alaimo K, Olson CM \& Frongillo EA Jr (2001) Food insufficiency and American school-aged children's cognitive, academic, and psychosocial development. Pediatrics 108, 44-53.

16. Jyoti DF, Frongillo EA \& Jones SJ (2005) Food insecurity affects school children's academic performance, weight gain, and social skills. J Nutr 135, 2831-2839.

17. Connell CL, Lofton KL, Yadrick K \& Rehner TA (2005) Children's experiences of food insecurity can assist in understanding its effect on their well-being. J Nutr 135, $1683-1690$.

18. Food and Agriculture Office of the United Nations (2006) Prevalence of Undernourishment in Total Population. http://www.fao.org/corp/countries/en/(accessed November 2008).

19. de Onis M, Blossner M, Borghi E, Morris R \& Frongillo EA (2004) Methodology for estimating regional and global trends of child malnutrition. Int J Epidemiol 33, 1260-1270.

20. UNICEF (2006) A Study of Child Vulnerability in Barbados, St. Lucia and St. Vincent \& the Grenadines. Christ Church, Barbados: UNICEF Office for Barbados and the Eastern Caribbean.

21. Webb P, Coates J, Frongillo EA, Rogers BL, Swindale A \& Bilinsky P (2006) Measuring household food insecurity: why it's so important and yet so difficult to do. J Nutr 136, 1404S-1408S.

22. Swindale A \& Bilinsky P (2006) Development of a universally applicable household food insecurity measurement tool: process, current status, and outstanding issues. J Nutr 136, 1449S-1452S.

23. US Department of Agriculture, Economic Research Service (2006) US Household Food Security Survey Module: Three-Stage Design, With Screeners. Washington, DC: USDA ERS.

24. Nord M (2006) US Household Food Security Survey Module: Six-Item Short Form. Washington, DC: USDA, ERS.

25. Maldonado G \& Greenland S (1993) Simulation study of confounder-selection strategies. Am J Epidemiol 138, 923-936.

26. Maitland K, Berkley JA, Shebbe M, Peshu N, English M \& Newton CR (2006) Children with severe malnutrition: can those at highest risk of death be identified with the WHO protocol? PLoS Med 3, e500.

27. Branca F (2006) Nutritional solutions to major health problems of preschool children: how to optimise growth and development. J Pediatr Gastroenterol Nutr 43, Suppl. 3, S4-S7.

28. Caballero B (2003) Global patterns of child health: the role of nutrition. Forum Nutr 56, 249-250.

29. Kuczmarski MF \& Weddle DO (2005) Position paper of the American Dietetic Association: nutrition across the spectrum of aging. J Am Diet Assoc 105, 616-633.

30. Weinreb L, Wehler C, Perloff J, Scott R, Hosmer D, Sagor L \& Gundersen C (2002) Hunger: its impact on children's health and mental health. Pediatrics 110, e41.

31. Guillford MC, Mahabir D \& Rocke B (2003) Food insecurity, food choices, and body mass index in adults: nutrition transition in Trinidad and Tobago. Int J Epidemiol 32, 508-516. 